\title{
Rates of sickness absenteeism among employees of a modern hospital: the role of demographic and occupational factors
}

\author{
A PINES, ${ }^{1} \mathrm{~K}$ SKULKEO,' E POLLAK, ${ }^{3}$ E PERITZ, ${ }^{2}$ AND J STEIF ${ }^{3}$ \\ From the Department of Occupational Health ${ }^{1}$ and School of Public Health, ${ }^{2}$ Hebrew University-Hadassah \\ Medical School, and Hadassah Medical Organisation, ${ }^{3}$ Jerusalem, Israel
}

ABSTRACT Sickness absenteeism, of hospital employees particularly, is a problem of concern due to its negative economic and morale impacts. The aim of the first stage of the study was to identify according to some demographic (sex, age, marital status) and occupational (occupational group, duration of hospital employment) variables those groups of hospital employees who are at higher risk of sickness absenteeism. A comparison with the data of the study performed in the same hospital about 15 years ago showed a rise in the duration of absences with a simultaneous reduction in their incidence. Sickness absenteeism was higher among female, mainly unskilled, workers, presently or previously married, aged from 45 to 60 , and employed in the hospital for over ten years. Continuous social and medical surveillance of these employees is suggested as a promising way of reducing sickness absenteeism.

Certain trends in hospital development in the past decades have posed several problems to the occupational health services of hospital personnel..$^{1-4}$ Among these the most important seem to be:

(1) A steady increase in the hospital working population, especially by the introduction of several new occupations, some of which have no direct relation with the patients' bedside care and employ highly qualified technical personnel.

(2) The introduction of new types of equipment and chemical compounds, some of which represent a potential hazard to health.

(3) The intensification of work processes (manual and especially mental overload), frequent stress, and disturbances of circadian rhythms.

These trends and the consequent problems were discussed recently at the first International Congress for Safety, Health and Well-being at Hospitals, convened in The Hague in October 1981.

Sickness absenteeism or "absenteeism attributable by employers to sickness" as it is usually defined $^{5-9}$ is a matter of concern for the manage-

Received 11 July 1984 Accepted 13 August 1984 ment and occupational health services of hospitals as well as other enterprises because of its economical consequences and its adverse effects on workers' morale. Therefore sickness absenteeism has to be reduced to reasonable proportions after a careful analysis of its trends and causes.

Most reports on sickness absenteeism among hospital workers refer to the nursing staff $^{10-13}$; earlier studies have been reviewed by Redfern. ${ }^{14}$ Investigations on sickness absenteeism and related health problems of other occupational groups employed in hospitals are less numerous. ${ }^{515-18}$ Among these, that of Mann et $a l^{15}$ is of special interest since it was performed during the years $1965-6$ in the same hospital at which the present study was carried out. We could therefore look at trends of sickness absenteeism in the hospital staff by comparing the present data with those obtained about 15 years ago.

Our purposes were to analyse the extent of sickness absenteeism in a modern hospital and its relation to such factors as sex, age, marital status, workers' occupation, and duration of hospital employment in order to identify the groups of hospital em- $\stackrel{\mathscr{C}}{?}$ ployees with raised levels of sickness absenteeism. $T$ We considered that such high risk groups should be the primary object of any programme designed to reduce sickness absenteeism. 


\section{Methods and population}

The study was based on the sickness absence records routinely completed in the personnel and occupational health departments of the Jerusalem Hadassah Hospital for 1981. These records were partly computerised and contained the following data: the number of spells of absence and of days lost for each employee together with his sex, age, marital status, occupation, and duration of employment in the hospital.

Data on the distribution of the hospital employees according to these variables were obtained from the personnel department's computerised files for 1981 . The figures referring to the beginning and the end of the study period ( 1 January and 31 December) were averaged and used to calculate the following indicators of absenteeism:

(a) mean number of spells of absence a year per worker;

(b) mean number of spells of absence a year per absentee;

(c) mean number of calendar days lost a year per worker;

(d) mean number of calendar days lost a year per absentee; and

(e) mean duration of the spells of absence.

Since the distribution patterns obtained for the spells of absence and for the days lost due to sickness are generally not symmetrical ${ }^{519}$ the statistical estimation of these parameters based on the arithmetical mean and standard devition may lead to misinterpretation (in particular within smaller subgroups). To avoid erroneous inferences the frequency distribution of the employees, and of the absentees only, by the number of spells of absence and of days lost has also been analysed. Workers who reported seven or more spells of absence or 20 or more days lost during the year were considered "heavy absentees".

The statistical evaluation of the differences between the means and the distributions of the parameters analysed in various segments of the hospital staff was performed using $t$ (Student's) and $\chi^{2}$ (Chisquare) tests and analysis of variance; $p<0.05$ was adopted as the marginal level of significance.

The study population of 3020 employees (the total staff of the Ein Karem Hadassah Hospital, Jerusalem) was distributed according to the demographic and occupational variables as follows:

Women predominated in the working population and constituted $60.7 \%$ of the total.

The mean age of the employees was 39.9 (SD 11.9 ); the mode was 29 years, the median, 37.6 years. Two thousand and seventy six employees $(68.8 \%)$ were under 45 and $61(2.0 \%)$ were aged 65
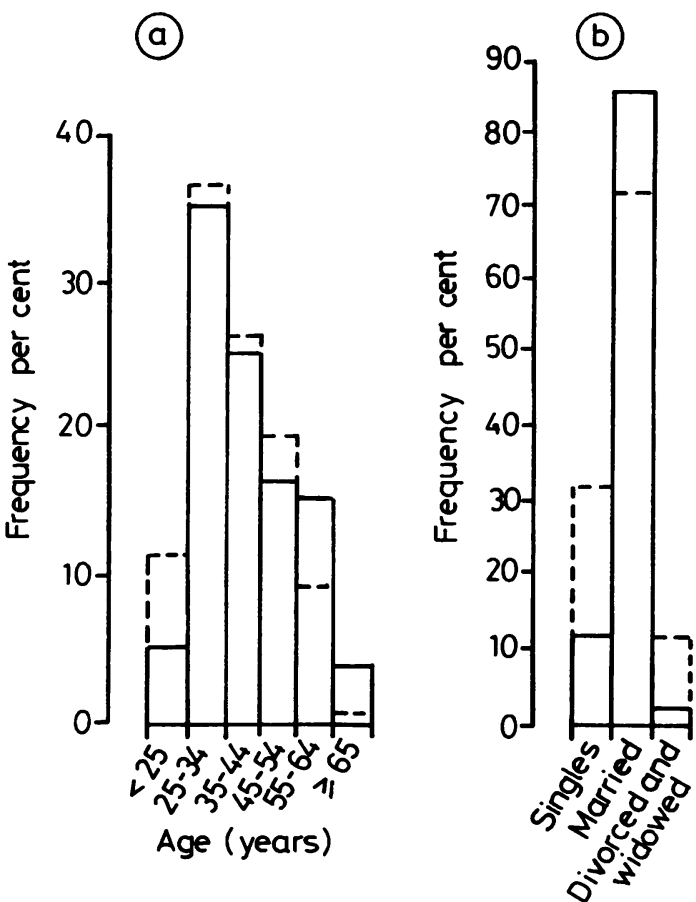

Fig 1 Percentage frequency distribution of hospital staff by sex and age $(A)$ and by sex and marital status (B). Solid lines - men, dash lines - women.

or more. The frequency distribution of male and female workers by age were significantly different with more women in the younger and more men in the older age groups (fig 1).

Married workers strongly predominated, comprising $76.8 \%(2315)$ of the total number of workers, whereas those never married, the divorced, and widowed constituted altogether only $23.2 \%$ of the total $(18.3 \%, 2.6 \%$, and $2.3 \%$, respectively). Male workers predominated in the married category and women in the others. The distributions of men and women according to marital status were significantly different.

The distribution of hospital personnel according to occupation was as follows:

(1) 623 doctors (medical doctors and dentists);

(2) 843 nurses (qualified and practical nurses and nurses' aides);

(3) 414 technicians (radiological, ECG, EEG, laboratory, and other);

(4) 405 administrative and clerical workers;

(5) 146 skilled workers;

(6) 431 unskilled workers, and

(7) 144 other occupations.

The distribution of the employees in these groups 
according to sex, age, marital status, and duration of employment differed significantly. Men strongly predominated in the groups of doctors and skilled workers, whereas there were more women among nurses, technicians, and clerical workers. Age distinctions were less pronounced; nevertheless, employees older than 45 predominated in the group of unskilled workers (about 58\%), whereas in the groups of doctors, nurses, and technicians they constituted only $22 \%, 25 \%$, and $25 \%$, respectively. As for the duration of employment the pattern of workers' distribution was relatively similar to that of the age distribution.

The mean duration of employment for the total hospital working population was $9 \cdot 1$ years (SD 8.9); the mode was 10.0 years and the median 6.0 years. The hospital staff was classified according to duration of employment into five groups: less than one year (357), one to five years (979), six to nine years (705), ten to 19 years (558), and 20 years and more (421). More men (18.1\%) had been employed for 20 years and over than women $(11 \cdot 2 \%)$.

The crude absenteeism data referring to the hospital workers employed for less than one year did not correctly reflect the absenteeism rates of this group since during a whole year these employees might had have more spells of absence and more days lost. To obtain reliable and comparable figures a correction of respective absenteeism rates appeared necessary. For this purpose the mean duration of employment was calculated for the subgroup of recently employed workers and found to be 0.55 years, and a correction factor of 1.82 was drawn. The absenteeism figures were multipled by this factor and used for the subsequent analysis.

Repeated breakdown of the working population was performed to obtain subgroups homogenous by more than one variable. As in certain cases the subgroups were too small to avoid non-valid conclusions absenteeism rates calculated on the base of fewer than 20 people were excluded from further analysis.

To eliminate the confounding effects of different demographic and occupational factors on absenteeism rates, the latters have been standardised using an indirect method..$^{20} \mathrm{~A}$ paper dealing with confounding effects in a more comprehensive way by multiple regression and analysis of variance, is in preparation.

\section{Results and comments}

During the study period (1 January 1981 to 31 December 1981) 8146 reported spells of absence with 34829 days lost were attributed to sickness. This was equivalent to the absence from work of about 100 workers (3.1\% of the entire manpower) for the whole year.

The comparison the absenteeism rates calculated from these figures with those reported ${ }^{15}$ for the years 1965-6 shows an obvious decrease in the proportion of absentees among the entire working population and of the mean number of spells of absence per worker per year. On the other hand the mean number of days lost per worker and, especially, per absentee increased as did the mean duration of the spells of absence (table 1).

During this 15 year period the hospital management had succeeded in significantly reducing the number of short term, particularly one day noncertified, spells of absence. At the same time the prolongation of the mean duration of the spells of absence may reflect either the occurrence of more serious diseases or the employees' desire to take advantage of their right for compensation for sick leave.

The absentees' distribution according to the number of spells of absence and days lost during 1981 was as follows: $21 \%$ of all the absentees were absent only once during the year, $30.4 \%$ two or three times, $30.7 \%$ four to six times, and $17.9 \%$ more than six times. As for the number of days lost, $8.9 \%$ of all the absentees lost only one working day during the whole year, $24.7 \%$ lost from two to five days, $18.1 \%$ from six to nine days, $22.7 \%$ from ten to 19 days, and $25.6 \% 20$ days or more. Thus about a quarter of all the absentees (about one sixth of the entire hospital personnel) may be considered as heavy absentees.

Additional information was obtained from the

Table 1 Absenteeism rates in the Jerusalem Hadassah Hospital

\begin{tabular}{lccc}
\hline Parameters of absenteeism & $1965-6^{*}$ & 1981 & 1981 as percentage of 1965-6 \\
\hline Mean number of spells of absence per worker a year & $3 \cdot 0$ & $2 \cdot 7$ & $90 \cdot 0$ \\
Mean number of days lost per worker a year & $10 \cdot 6$ & $11 \cdot 5$ & $108 \cdot 5$ \\
Mean number of days lost per spell of absence & $3 \cdot 5$ & $4 \cdot 3$ & $122 \cdot 9$ \\
Proportion of absentees among hospital personnel (\%) & $79 \cdot 0$ & $66 \cdot 0$ & $84 \cdot 3$ \\
Mean number of spells of absence per absentee a year & $4 \cdot 1 \dagger$ & $4 \cdot 1$ & $100 \cdot 0$ \\
Mean number of days lost per absentee a year & $14 \cdot 7 \dagger$ & $17 \cdot 3$ & 117.7 \\
\hline
\end{tabular}

*Mann et al. ${ }^{15}$

†Calculated by us by Mann et al ${ }^{15}$ data. 

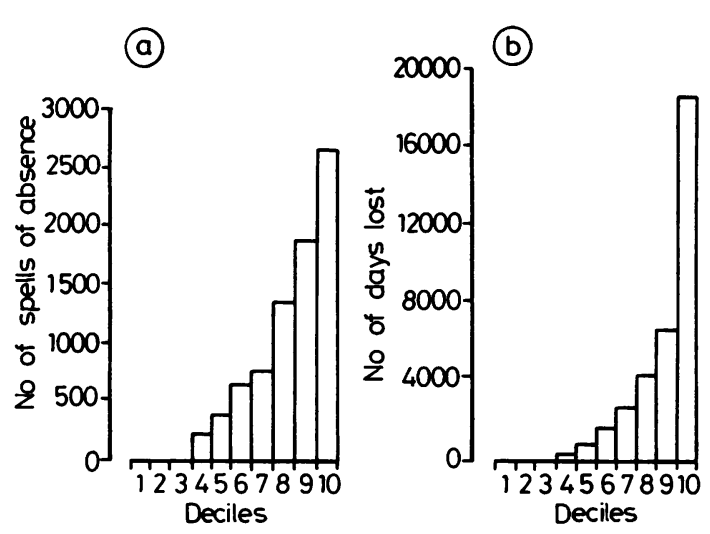

Fig 2 Decile distribution of hospital employees according to number of spells of absence (a) and number of days lost (b).

analysis of the decile distribution of hospital employees according to the number of spells of absence and days lost which ranged from 0 to 2660 and from 0 to 18515 per decile, respectively. The mean numbers of spells of absence and of days lost per worker increased exponentially in successive deciles from 0 to 8.8 and from 0 to $61 \cdot 3$, respectively. The last decile accounted for about one third of all spells of absence that occurred during the year and for more than a half of the total number of days lost by the entire hospital staff (fig 2). Careful identification of this group of workers and elucidation of the major causes of their poor work attendance as well as contributing factors may help in elaboration of an absenteeism prevention programme.

There was a clear relation between the number of spells of absence and the number of days lost. The absentees who had been absent only once during the year accounted for $6.2 \%$ of the total number of days lost, those with two or three spells of absence for $17.7 \%$, those with four to six for $33.9 \%$, and those with seven or more spells for $42.2 \%$.

SEX

The mean number of spells of absence and the mean number of days lost per worker were statistically significantly $(\mathrm{p}<0.001)$ higher in women than in men (table 2). The percentages of moderate and heavy absentees according to the number of spells of absence (four or more) or to the number of days lost (ten or more) were also higher in women than in men $(53.3 v 38.4 \%$ and $52.3 v 39.7 \%$, respectively). The distributions of employees by sex and each of these parameters were statistically significantly different $(\mathrm{p}<0.001)$ (fig 3):

The analysis of variance showed that sex exerted only a slight (less than $1 \%$ ) but statistically highly significant effect on the variation of the number of days lost $(\mathrm{p}<0.0001)$.

Higher absenteeism rates have been generally reported in women working in various enterprises. ${ }^{21}{ }^{22}$ Female absenteeism in the present study prevailed in all age groups (except for the 55-64 years group which contained a certain proportion of women of retirement age), in single and especially in married workers, and in different occupational groups. The only occupational group in which male absenteeism rates were higher than in their female counterparts was the group of nurses, probably due to the relative predominance of older people among the male nurses.

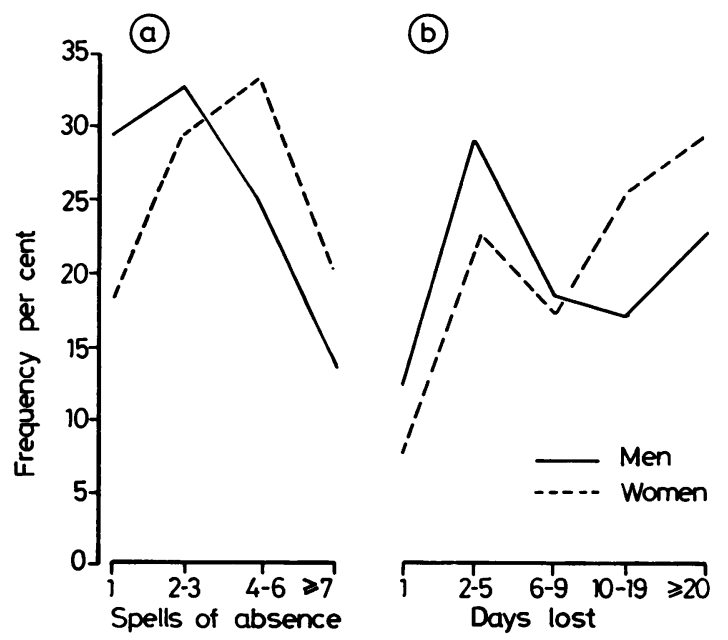

Fig 3 Percentage frequency distribution of male and female absentees by number of spells of absence (a) and number of days lost (b).

Table 2 Absenteeism rates by sex

\begin{tabular}{|c|c|c|c|c|c|c|c|}
\hline \multirow[t]{2}{*}{ Sex } & \multirow[t]{2}{*}{ No of workers } & \multicolumn{2}{|c|}{$\begin{array}{l}\text { Mean No of spells of absence } \\
\text { per: }\end{array}$} & \multicolumn{3}{|c|}{ Mean No of days lost per: } & \multirow{2}{*}{$\begin{array}{l}\text { Percentage of } \\
\text { absentees }\end{array}$} \\
\hline & & Worker & Absentee & Worker & Absentee & Spell of absence & \\
\hline $\begin{array}{l}\text { Men } \\
\text { Women }\end{array}$ & $\begin{array}{l}1184 \\
1834\end{array}$ & $\begin{array}{l}1 \cdot 85 \\
3 \cdot 25\end{array}$ & $\begin{array}{l}3 \cdot 43 \\
4 \cdot 34\end{array}$ & $\begin{array}{r}9.20 \\
13.05\end{array}$ & $\begin{array}{l}17 \cdot 05 \\
17 \cdot 46\end{array}$ & $\begin{array}{l}4 \cdot 98 \\
4 \cdot 02\end{array}$ & $\begin{array}{l}54 \cdot 0 \\
74 \cdot 7\end{array}$ \\
\hline
\end{tabular}


Table 3 Absenteeism rates by age

\begin{tabular}{|c|c|c|c|c|c|c|c|}
\hline \multirow[t]{2}{*}{ Age (years) } & \multirow[t]{2}{*}{ No of workers } & \multicolumn{2}{|c|}{$\begin{array}{l}\text { Mean No of spells of absence } \\
\text { per: }\end{array}$} & \multicolumn{3}{|c|}{ Mean No of days lost per: } & \multirow{2}{*}{$\begin{array}{l}\text { Percentage of } \\
\text { absentees }\end{array}$} \\
\hline & & Worker & Absentee & Worker & Absentee & Spell of absence & \\
\hline $\begin{array}{l}<25 \\
25-34 \\
35-44 \\
45-54 \\
55-64 \\
\geqslant 65\end{array}$ & $\begin{array}{r}256 \\
1071 \\
749 \\
539 \\
342 \\
61\end{array}$ & $\begin{array}{l}2.41 \\
2.39 \\
2.61 \\
3.45 \\
3.01 \\
2.46\end{array}$ & $\begin{array}{r}3.89 \\
3.76 \\
3.76 \\
4 \cdot 51 \\
4 \cdot 27 \\
10.71\end{array}$ & $\begin{array}{r}9 \cdot 01 \\
9 \cdot 50 \\
10 \cdot 64 \\
15 \cdot 87 \\
16.59 \\
4 \cdot 10\end{array}$ & $\begin{array}{l}14 \cdot 50 \\
14.96 \\
15 \cdot 30 \\
20 \cdot 76 \\
24.05 \\
18.86\end{array}$ & $\begin{array}{l}3.72 \\
3.98 \\
4.07 \\
4.60 \\
5.63 \\
1.67\end{array}$ & $\begin{array}{l}62 \cdot 1 \\
63 \cdot 5 \\
69 \cdot 4 \\
78 \cdot 1 \\
68 \cdot 7 \\
22 \cdot 9\end{array}$ \\
\hline
\end{tabular}

The observed difference in absenteeism rates between sexes may be at least partially attributed to the higher sense of family responsibility particularly inherent in married women..$^{23}{ }^{24}$ In our study the difference between absenteeism rates in married men and women was more pronounced than in singles.

\section{AGE}

The absenteeism rates were similar in the various age groups up to the age of 44 but increased abruptly in those aged 45-64, with a subsequent fall in those aged 65 and over. The prevalence of absentees, particularly heavy absentees in the working population, followed roughly the same age pattern (table 3).

Consequently, the workers were divided according to age into two groups: under 45 and 45-64.
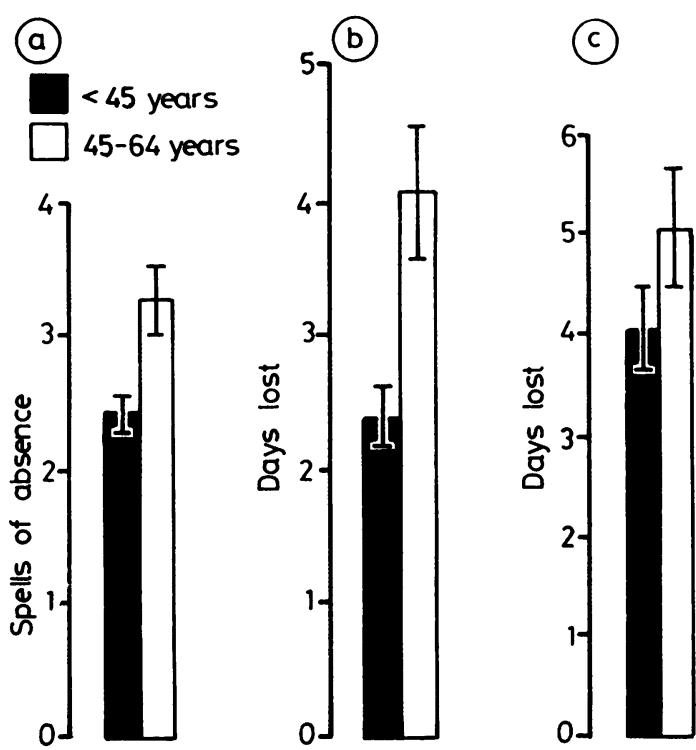

Fig 4 Absenteeism rates (mean $\pm S E \cdot t_{0.05}$ ) of hospital employees by age: mean number of spells of absence per worker (a) and mean number of days lost per worker (b) and per spell of absence (c).
Absenteeism rates in the older group were considerably higher than in the younger (fig 4).

The combined effect of age and sex on sickness absenteeism is summarised in fig 5 . In all age groups up to 54 women had more spells of absence and days lost than men. Up to the age of 44 a slight increase in absenteeism rates was observed among women but not among men. It was followed by a steep rise in women up to the age of 54 and in men up to the age of 64 . The subsequent fall of absenteeism rates occurred in woman aged 55-64 (with the exception of the number of days lost per absentee which was slightly raised). In men such a fall took place in the oldest age group (over 64). They showed absenteeism rates (except for the number of spells of absence per absentee) even lower than in the youngest male workers.

The role of age as one of determinants of the variation of the absenteeism rates is supported by the analysis of variance: about $2 \%$ of the variation in the number of days lost is attributed to the differences in the workers' age $(\mathrm{p}<0.0001)$.
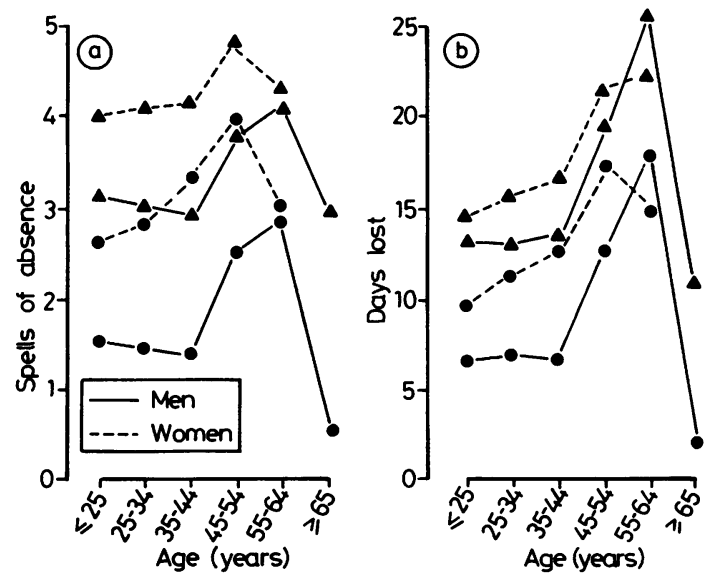

Fig 5 Absenteeism rates: mean numbers of spells of absence (a) and mean numbers of days lost (b) by sex and age of hospital employees. Circles represent all employees while triangles represent absentees only. 
Table 4 Absenteeism rates by marital status

\begin{tabular}{|c|c|c|c|c|c|c|c|}
\hline \multirow[t]{3}{*}{ Marital status } & \multirow[t]{3}{*}{ No of workers } & \multirow{2}{*}{\multicolumn{2}{|c|}{$\begin{array}{l}\text { Mean No of spells of absence } \\
\text { per: }\end{array}$}} & \multicolumn{3}{|c|}{ Mean No of days lost per: } & \multirow{3}{*}{$\begin{array}{l}\text { Percentage of } \\
\text { absentees }\end{array}$} \\
\hline & & & & \multirow{2}{*}{ Worker } & \multirow{2}{*}{ Absentee } & \multirow{2}{*}{ Spell of absence } & \\
\hline & & Worker & Absentee & & & & \\
\hline $\begin{array}{l}\text { Single } \\
\text { Married } \\
\text { Divorced } \\
\text { Widowed }\end{array}$ & $\begin{array}{r}553 \\
2317 \\
78 \\
71\end{array}$ & $\begin{array}{l}2 \cdot 06 \\
2 \cdot 83 \\
2 \cdot 99 \\
3 \cdot 51\end{array}$ & $\begin{array}{l}3 \cdot 48 \\
6 \cdot 10 \\
4 \cdot 48 \\
4 \cdot 79\end{array}$ & $\begin{array}{r}7 \cdot 11 \\
12 \cdot 31 \\
12 \cdot 09 \\
21 \cdot 78\end{array}$ & $\begin{array}{l}11 \cdot 99 \\
18 \cdot 06 \\
18 \cdot 13 \\
29 \cdot 73\end{array}$ & $\begin{array}{l}3 \cdot 45 \\
4 \cdot 35 \\
4 \cdot 04 \\
6 \cdot 21\end{array}$ & $\begin{array}{l}59 \cdot 3 \\
68 \cdot 1 \\
66 \cdot 7 \\
73 \cdot 2\end{array}$ \\
\hline
\end{tabular}

A general trend towards an increase in the extent of sickness absenteeism with age has been reported by others. ${ }^{22} 232526$ This fact may reflect the general deterioration in the state of health of those aged 45-64. The age of 44 may be considered a turning point in age related health changes which may essentially affect absenteeism rates, perhaps reflecting to some degree the adverse effects of long term exposure to the hazardous factors of the hospital environment.

A fact that requires special explanation is the drop in the absenteeism rates in the oldest (men 65 and over and women 55-64) age groups. These might be constituted of people who continue to work after the retirement age (65 for men and 60 for women) because they enjoy both good health and their professional activity. In women the drop in the absenteeism rates in the 55-64 years age group was much less pronounced than in the men of 65 and older. This female group only partly consisted of retirement age women so that the high absenteeism rates of women younger than 60 might mask the above described effects of the retirement age on sickness absenteeism.

With respect to absenteeism rates in employees before retirement an interesting observation was that of Mann et al who found an unexpected rise in sickness absenteeism one to two years preceding retirement. ${ }^{15}$ The authors explained this finding by "a possible tendency by some workers to make the fullest possible use of their unexpended accumulated sickness leave."

\section{MARITAL STATUS}

The single employees had the lowest, and the widowed the highest, rates of absenteeism. This trend applies to the mean number of spells of absence, the mean number of days lost per worker, per absentee, and per spell of absence, and the proportion of absentees, particularly heavy absentees. Married and divorced employees showed similar absenteeism rates and occupied the intermediate position between the single and the widowed, except for the mean number of spells of absence per absentee which was highest in the group of married workers (table 4).
The combined effect of marital status and sex on the absenteeism rates in the population under the study may be described as follows. The mean number of spells of absence and of days lost per worker in the male and female single subgroups were significantly lower than in respective married subgroups (for men-p $<0.01$ and $p<0.001$, respectively; for women $p<0.0001$ for both parameters). Absenteeism rates in the groups of divorced and widowed women were similar to those of the married. The mean numbers of spells of absence per worker in single and married women were higher than in respective male subgroups $(p<0.0001)$. As for the mean number of days lost per worker, a statistically significant female preponderance was observed only in the married subgroups (fig 6).
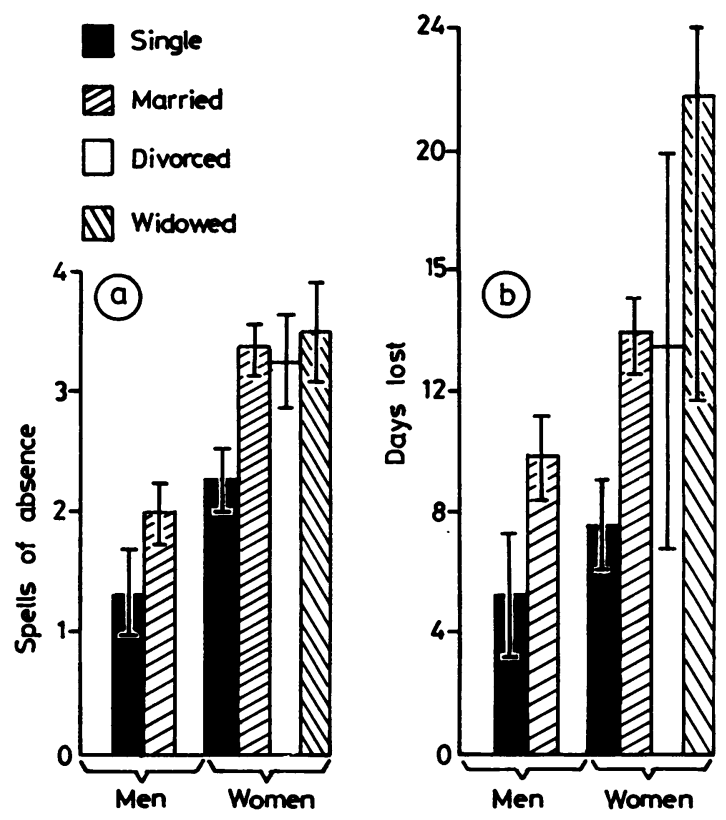

Fig 6 Absenteeism rates (mean $\pm S E \cdot t_{0.05}$ ): mean number of spells of absence (a) and mean number of days lost (b) per worker by sex and marital status of hospital employees. 
Table 5 Absenteeism rates by occupational groups

\begin{tabular}{|c|c|c|c|c|c|c|c|}
\hline \multirow{3}{*}{$\begin{array}{l}\text { Occupational } \\
\text { groups }\end{array}$} & \multirow[t]{3}{*}{ No of workers } & \multirow{2}{*}{\multicolumn{2}{|c|}{$\begin{array}{l}\text { Mean No of spells of absence } \\
\text { per: }\end{array}$}} & \multicolumn{3}{|c|}{ Mean No of days lost per: } & \multirow{3}{*}{$\begin{array}{l}\text { Percentage of } \\
\text { absentees }\end{array}$} \\
\hline & & & & \multirow{2}{*}{ Worker } & \multirow{2}{*}{ Absentee } & \multirow{2}{*}{ Spell of absence } & \\
\hline & & Worker & Absentee & & & & \\
\hline $\begin{array}{l}\text { Doctors } \\
\text { Nurses } \\
\text { Technicians } \\
\text { Clerks } \\
\text { Skilled workers } \\
\text { Unskilled workers } \\
\text { Other occupations }\end{array}$ & $\begin{array}{l}623 \\
843 \\
414 \\
405 \\
146 \\
431 \\
144\end{array}$ & $\begin{array}{l}0 \cdot 64 \\
2 \cdot 94 \\
2 \cdot 59 \\
3 \cdot 72 \\
3 \cdot 47 \\
4 \cdot 28 \\
2 \cdot 21\end{array}$ & $\begin{array}{l}2 \cdot 09 \\
3 \cdot 86 \\
3 \cdot 70 \\
4 \cdot 93 \\
4 \cdot 26 \\
5 \cdot 08 \\
3 \cdot 38\end{array}$ & $\begin{array}{r}4 \cdot 38 \\
11 \cdot 59 \\
10 \cdot 17 \\
13 \cdot 80 \\
13 \cdot 30 \\
20 \cdot 43 \\
10 \cdot 48\end{array}$ & $\begin{array}{l}14 \cdot 27 \\
15 \cdot 22 \\
14 \cdot 52 \\
18 \cdot 32 \\
16 \cdot 32 \\
24 \cdot 26 \\
16 \cdot 05\end{array}$ & $\begin{array}{l}6 \cdot 83 \\
3 \cdot 94 \\
3 \cdot 92 \\
3 \cdot 71 \\
3 \cdot 83 \\
4 \cdot 78 \\
4 \cdot 75\end{array}$ & $\begin{array}{l}30 \cdot 7 \\
76 \cdot 1 \\
70 \cdot 0 \\
75 \cdot 3 \\
81 \cdot 5 \\
84 \cdot 2 \\
66 \cdot 0\end{array}$ \\
\hline
\end{tabular}

This association between absenteeism levels and marital status has also been reported elsewhere. ${ }^{14} 27$ The most frequent findings have been that married women show higher absenteeism rates than single women and married men; this was also true for our study population. Married people are generally older than single and divorced, and widowed people are generally older than those who are married. Thus age cannot be neglected as a determinant in the shaping of these absenteeism rates. Nevertheless, as was found by Mann et al, ${ }^{15}$ among women belonging to the same age group the married have higher absenteeism rates than the single, whereas divortees and widows have the highest absenteeism level. Thus family and especially maternal responsibilities may be the major cause of an increased sickness absenteeism in married, divorced, and widowed women. Family responsibilities may also account for a higher absenteeism rates in married male workers by comparison with the single.

\section{OCCUPATIONAL GROUPS}

The highest rates of sickness absenteeism were observed in the group of unskilled workers: the mean number of spells of absence and the mean number of days lost per worker and per absentee in this group were significantly higher than in all other occupational groups, except for skilled workers. The highest proportion of absentees and particularly heavy absentees with 20 or more days lost during the year were also found in the group of unskilled workers. By contrast, doctors had lower rates of absenteeism than others: the mean number of spells of absence per worker $(p<0.0001)$ and per absentee, the mean number of days lost per worker $(p<0.0001-0.01)$ and per absentee, percentages of absentees, and especially heavy absentees. The only exception was the mean duration of the spells of absence that exhibited the highest value in this occupational group.

With respect to other occupational groups it should be pointed out that in nurses and technicians (medical staff) the rates of absenteeism were somewhat lower than in the groups of skilled and clerical workers (auxiliary staff) (table 5).

The differences in the distributions of workers of the various occupational groups according to the number of spells of absence or the number of days lost during the year were found to be highly significant $(p<0.0001)$. Analysis of variance showed that the variation of the number of days lost was essentially affected by occupational factor ( $\mathrm{p}<0001$ ), accounting for a higher proportion than either sex or age (5\% v1\% and $2 \%$, respectively).

The differences in the distribution of the various occupational groups by sex, age, marital status, and duration of employment suggested that these differences and not the occupational factor itself bore the primary responsibility for the diversity in the absenteeism rates in the occupational groups of hospital personnel. To test this hypothesis, the absenteeism rates in the various occupational groups were stan-

Table 6 Absenteeism rates by occupational groups standardised by sex, age, marital status, and duration of employment

\begin{tabular}{|c|c|c|c|c|c|c|c|c|c|c|}
\hline \multirow{2}{*}{$\begin{array}{l}\text { Occupational } \\
\text { groups }\end{array}$} & \multicolumn{5}{|c|}{ Mean No of spells of absence per worker } & \multicolumn{5}{|c|}{ Mean No of days lost per worker } \\
\hline & $\begin{array}{l}\text { Crude } \\
\text { rate }\end{array}$ & Sex & $\begin{array}{l}\text { Sex }+ \\
\text { age }\end{array}$ & $\begin{array}{l}\text { Sex }+ \text { marital } \\
\text { status }\end{array}$ & $\begin{array}{l}\text { Sex + duration } \\
\text { of employment }\end{array}$ & $\begin{array}{l}\text { Crude } \\
\text { rate }\end{array}$ & Sex & $\begin{array}{l}\text { Sex }+ \\
\text { age }\end{array}$ & $\begin{array}{l}\text { Sex + marital } \\
\text { status }\end{array}$ & $\begin{array}{l}\text { Sex + duration } \\
\text { of employment }\end{array}$ \\
\hline $\begin{array}{l}\text { Doctors } \\
\text { Nurses } \\
\text { Technicians } \\
\text { Clerks } \\
\text { Skilled workers } \\
\text { Unskilled workers } \\
\text { Other occupations }\end{array}$ & $\begin{array}{l}0 \cdot 64 \\
2 \cdot 94 \\
2 \cdot 59 \\
3 \cdot 72 \\
3 \cdot 47 \\
4 \cdot 28 \\
2 \cdot 21\end{array}$ & $\begin{array}{l}0 \cdot 82 \\
2 \cdot 49 \\
2 \cdot 41 \\
3 \cdot 55 \\
4 \cdot 84 \\
4 \cdot 50 \\
2 \cdot 23\end{array}$ & $\begin{array}{l}0 \cdot 88 \\
2 \cdot 53 \\
2 \cdot 41 \\
3 \cdot 52 \\
4 \cdot 72 \\
4 \cdot 13 \\
2 \cdot 21\end{array}$ & $\begin{array}{l}0 \cdot 88 \\
2 \cdot 54 \\
2 \cdot 48 \\
3 \cdot 53 \\
4 \cdot 62 \\
4 \cdot 34 \\
2 \cdot 30\end{array}$ & $\begin{array}{l}0 \cdot 88 \\
2 \cdot 47 \\
2 \cdot 41 \\
3 \cdot 49 \\
4 \cdot 65 \\
4 \cdot 19 \\
2 \cdot 52\end{array}$ & $\begin{array}{r}4 \cdot 38 \\
11 \cdot 59 \\
10 \cdot 17 \\
13 \cdot 80 \\
13 \cdot 30 \\
20 \cdot 43 \\
10 \cdot 48\end{array}$ & $\begin{array}{r}5 \cdot 11 \\
10 \cdot 41 \\
9 \cdot 71 \\
13 \cdot 44 \\
16 \cdot 31 \\
21 \cdot 17 \\
10 \cdot 57\end{array}$ & $\begin{array}{r}5 \cdot 79 \\
10 \cdot 51 \\
9 \cdot 91 \\
13 \cdot 08 \\
15 \cdot 80 \\
18 \cdot 36 \\
10 \cdot 79\end{array}$ & $\begin{array}{r}5 \cdot 09 \\
10 \cdot 49 \\
10 \cdot 13 \\
13 \cdot 23 \\
16 \cdot 27 \\
15 \cdot 59 \\
11 \cdot 13\end{array}$ & $\begin{array}{r}5.68 \\
10 \cdot 37 \\
9.76 \\
12.92 \\
15.64 \\
19.38 \\
11.76\end{array}$ \\
\hline
\end{tabular}


Table 7 Absenteeism rates by duration of hospital employment

\begin{tabular}{|c|c|c|c|c|c|c|c|}
\hline \multirow{3}{*}{$\begin{array}{l}\text { Duration of } \\
\text { employment } \\
\text { (years) }\end{array}$} & \multirow[t]{3}{*}{ No of workers } & \multirow{2}{*}{\multicolumn{2}{|c|}{$\begin{array}{l}\text { Mean No of spells of absence } \\
\text { per: }\end{array}$}} & \multicolumn{3}{|c|}{ Mean No of days lost per: } & \multirow{3}{*}{$\begin{array}{l}\text { Percentage of } \\
\text { absentees }\end{array}$} \\
\hline & & & & Worker & Absentee & Spell of absence & \\
\hline & & Worker & Absentee & & & & \\
\hline $\begin{array}{c}<1 \\
1-5 \\
6-9 \\
10-19 \\
\geqslant 20\end{array}$ & $\begin{array}{l}357 \\
979 \\
705 \\
558 \\
421\end{array}$ & $\begin{array}{l}1 \cdot 22 \\
2.42 \\
3 \cdot 11 \\
3.24 \\
3.72\end{array}$ & $\begin{array}{l}2 \cdot 09 \\
3 \cdot 72 \\
4 \cdot 08 \\
4 \cdot 25 \\
5 \cdot 24\end{array}$ & $\begin{array}{r}6 \cdot 26 \\
9 \cdot 62 \\
12 \cdot 49 \\
14 \cdot 68 \\
17 \cdot 48\end{array}$ & $\begin{array}{l}10 \cdot 64 \\
14 \cdot 76 \\
16 \cdot 36 \\
19 \cdot 22 \\
24 \cdot 62\end{array}$ & $\begin{array}{l}5 \cdot 08 \\
3 \cdot 96 \\
4 \cdot 01 \\
4 \cdot 52 \\
4 \cdot 69\end{array}$ & $\begin{array}{l}58 \cdot 8 \\
65 \cdot 2 \\
76 \cdot 3 \\
72 \cdot 8 \\
71 \cdot 0\end{array}$ \\
\hline
\end{tabular}

dardised by sex alone, and by sex with age, or marital status, or duration of employment.

Standardisation by sex resulted in an essential (more than $20 \%$ of the crude rate level) increase in the mean number of spells of absence per worker in the doctors and skilled workers and in the mean number of days lost per worker among skilled workers. The strong preponderance of men in these groups is a likely explanation for this increase. Additional standardisation by age, or marital status, or duration of employment did not result in substantial changes in the mean number of spells of absence. As for the mean number of days lost, additional standardisation by age, or by duration of employment considerably increased the rate in the doctors' group and reduced the effect exerted by standardisation by sex only in the group of skilled workers. Standardisation by sex and marital status resulted in a decrease in the mean number of days lost per unskilled worker (table 6).

The inference to be drawn from these data might be that occupationally related distinctions in sick-
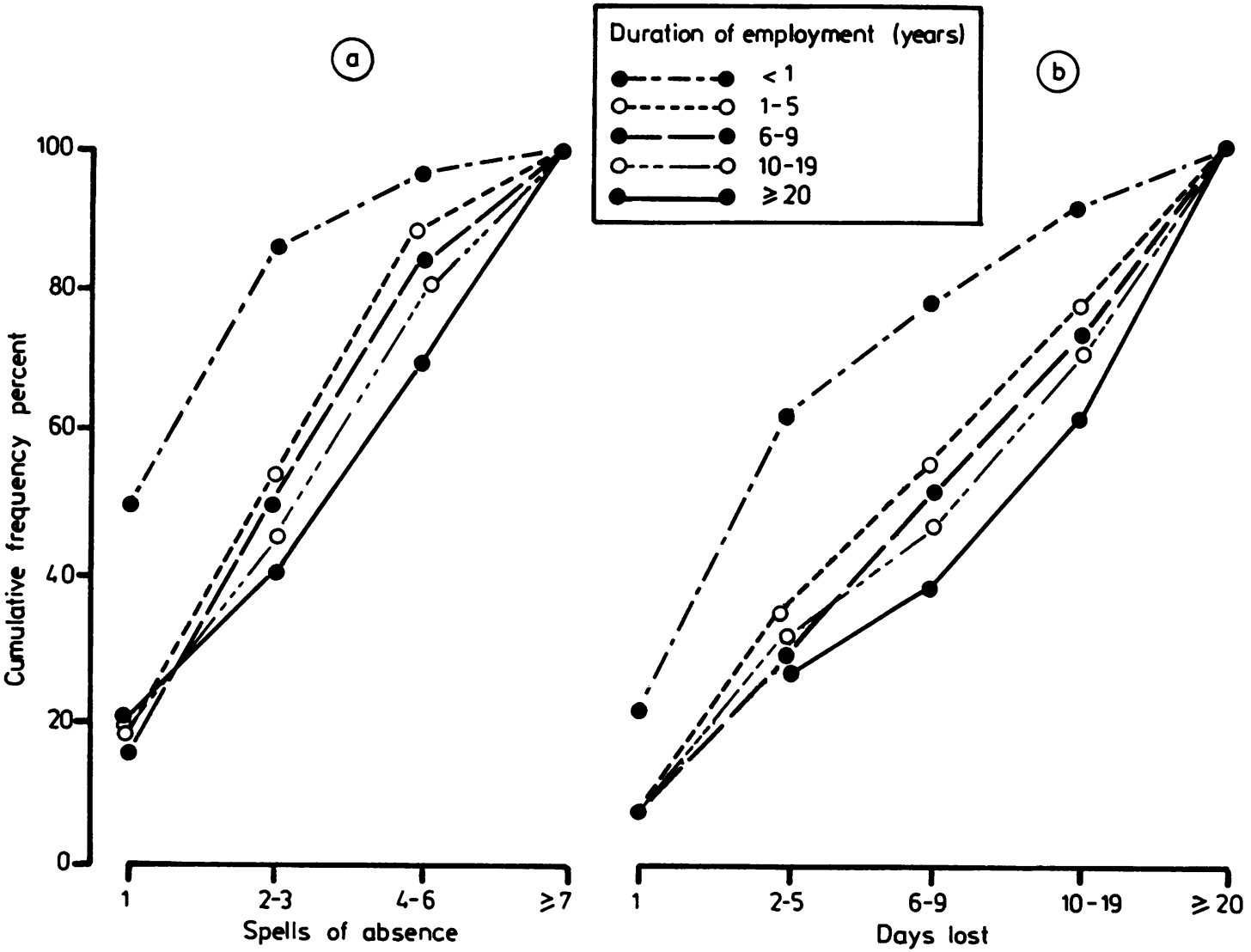

Fig 7 Cumulative percentage frequency distribution of absentees by duration of hospital employment and number of spells of absence (a) or days lost (b) per absentee. 
ness absenteeism in the hospital personnel may be only partly attributed to the differences in the respective groups distribution by sex and hardly to age, marital status, and duration of employment.

Occupational, social, and psychological factors contribute substantially to the sickness absenteeism pattern in various groups of workers. ${ }^{28-33}$ To explain the observed differences in the absenteeism rates in our study between doctors and the skilled and unskilled workers the following factors should be considered.

(a) The doctors seem to have the unofficial privilege of being away from their job without a medical certificate-that is, unrecorded;

(b) The doctors may continue to work despite some illness or health related discomfort because of a job specific sense of dedication and responsibility;

(c) The skilled and unskilled workers are obliged to justify each spell of absence, since the recording is fairly complete; and

$(d)$ The skilled and unskilled workers take advantage of their right to 30 days a year sickness leave more than other occupational groups.

Other factors such as mental and physical overload, shift work, adverse effects of occupational exposure to physical, chemical, and biological hazardous agents inherent in different hospital microenvironments, commuting, job satisfaction and job status (permanent or temporary) may strongly influence the sickness absenteeism pattern in the various occupational groups and their subgroups. Further epidemiological processing of the individual absenteeism records might be useful to evaluate the impact of these factors on the features of sickness absenteeism in hospital personnel.

\section{DURATION OF HOSPITAL EMPLOYMENT}

Absenteeism rates increased with seniority more steeply during the first decade than during the following ones. The mean number of spells of absence and the mean number of days lost per worker in the recently employed group were considerably lower than in all other groups classified according to tenure $(p<0.001)$ (table 7).

It was also found that there was a significant difference in the distribution of workers by duration of employment and the number of days lost $(p<$ 0.0001 ) and in the distribution of absentees by duration of employment and the number of spells of absence $(p<0.0001)$. There was an obvious rise in the proportion of heavy absentees with an increase in the duration of employment (fig 7). Analysis of variance showed that about $3 \%$ of the variation of the number of days lost per worker was attributable to the effect of seniority $(p<0.0001)$. The rise of absenteeism rates (except for the mean duration of

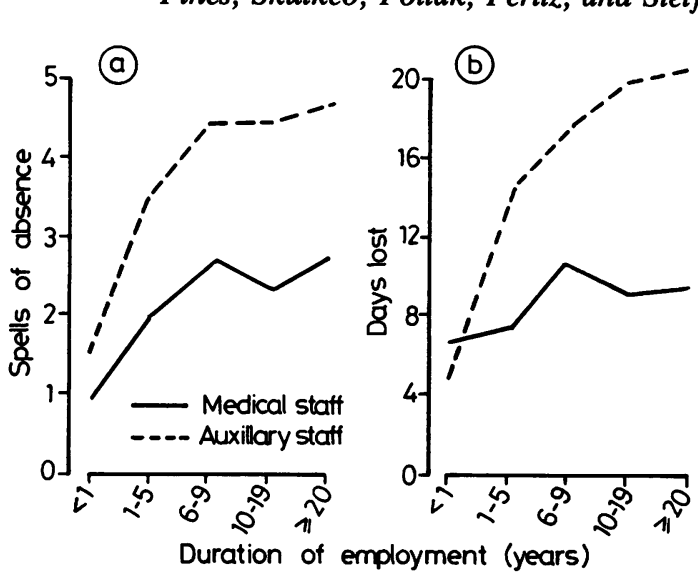

Fig 8 Absenteeism rates: mean numbers of spells of absence (a) and mean numbers of days lost (b) per worker $\mathcal{N}$ in medical and auxiliary hospital staff by duration of employment in hospital.

the spell of absence) with duration of employment isw in agreement with the data of the previous investigation. ${ }^{15}$

This dependence of absenteeism rates on seniority may reflect the effect of age on sickness absenteeism. Indeed, a positive correlation between age and duration of employment $(r=0.60)$ was found in our study population. Nevertheless, standardisation by⿳亠丷厂 age did not materially affect the absenteeism pattern according to duration of employment.

To elucidate the combined effect of occupation? and duration of employment on sickness absenteeism, the changes in absenteeism rates in relation to seniority were compared in various occupational groups. The auxiliary hospital staff (clerical, skilled $\mathbb{\Phi}$ and particularly unskilled workers) showed a pronounced increase in absenteeism rates with the 3 duration of employment, whereas among medica $\bar{h}$. employees (doctors, nurses, and technicians) such an increase was less conspicuous, being practically absent in the group of doctors. Consequently, thedifferences in absenteeism rates between these occupational groups (auxiliary $v$ medical staff and unskilled workers $v$ doctors) were small in recently or (less than one year) employed workers and increased significantly in the subgroups with higher seniority (fig 8). This phenomenon may bew explained by the fact that occupationally related effects on the workers' health and sickness absentee ism have a cumulative nature and may develop onlys after some period of work.

\section{Conclusions}

From the data obtained in this study it may be con- $\frac{\mathbb{D}}{2}$ 
cluded that currently or previously married female workers, especially unskilled, aged from 45 to 60 , and employed in the hospital for more than ten years represent the sector of hospital personnel with the highest sickness absenteeism records. Hence, these people may be considered a high sickness absenteeism risk group.

The identification of the additional factors, particularly the most common medical causes of sickness, as well as social, economical, psychological, etc, contributing to the rise of the sickness absenteeism rates seems to be of value as a crucial step in elaborating a comprehensive programme aimed at the reduction of sickness absenteeism among hospital personnel.

Requests for reprints to: Dr A Pines, Department of Occupational Health, Hebrew UniversityHadassah Medical School, POB 1172, Jerusalem 91010, Israel.

\section{References}

' Lunn JA. The health of staff in hospitals. London: William Heinemann Medical Books Ltd, 1975.

${ }^{2}$ Harrington JM. The health industry. In: McDonald JC, ed. Recent advances in occupational health. Vol 1. London: Churchill Livingstone, 1981:75-84.

${ }^{3}$ World Health Organisation. Occupational hazards in hospitals. Geneva: WHO, 1983. (EURO reports and studies 80.)

4 Brown TC, Kreider SD, Lange WR. Guidelines for employee health services in hospitals, clinics and medical research institutions. J Occup Med 1983;25:771-3.

${ }^{5}$ Anonymous. Sickness absence in hospital staff [Editorial]. Lancet 1979;ii: 1278-9.

- Permanent Commission and International Association on Occupational Health. Sub-committee on absenteeism. Draft recommendations. Br J Ind Med 1973;30:402-3.

7 Tyrer FH, Lee K. A synopsis of occupational medicine. Bristol: John Wright and Sons Ltd, 1979:60-5.

8 Taylor P. Aspects of sickness absence. In: Gardner AW, ed. Current approaches to occupational medicine. Bristol: John Wright and Sons Ltd, 1979:322-38.

'Ferguson D. Sickness absence: an analysis of the problem. Med J Australia 1973;1:334-9.

${ }^{10}$ Stephens TA, Burroughs WA. An application of operant conditioning to absenteeism in hospital setting. J Appl Psychol 1978;63:518-21.

" Colligan MJ, Frockt IJ, Tasto DL. Frequency of sickness absence and worksite clinic visits among nurses as a function of shift. Applied Ergonomics 1979;10:79-85.
${ }^{12}$ Clarke S, Hussey DG. Sickness absence amongst nuirsing staff at two hospitals. J Soc Occup Med 1979;29:126-30.

${ }^{13}$ Bureau N, Genin MG. Absenteeism of health care personnel: socio-economic approach. Gestions Hospitalieres 1981;205:343-60. (In French.)

14 Redfern SJ. Absence and wastage in trained nurses: a selective review of the literature. $J$ Adv Nurs 1978;3:231-49.

is Mann KJ, Abramson JH, Camrass J, Alon J. Sickness absenteeism in a hospital in Israel. Hospital 1971; (September):30711.

${ }^{16}$ Kearney JM, Smith AA. Sickness patterns in hospital staff. Occupational Health 1977;29:162-5.

${ }^{17}$ Snyder SM. Controlling absenteeism can help curb hospitals' costs. Hospitals 1978;52:102-3.

${ }^{18}$ Baird R. Illness-absences of hospital employees. Am J Public Health 1982;72:89.

19 Rushmore $\mathrm{CH}$, Youngblood SA. Medically related absenteeism: random or motivated behavior? J Occup Med 1979;21:24550.

${ }^{20}$ Lancaster HO. An introduction to medical statistics. New York: John Wiley and Sons, 1974:79-83.

${ }^{21}$ Machnikowski R, Plesnar BJ, Sitkiewicz G, Wiercinska J. Problems of sickness absenteeism on the basis of investigations performed in Lodz in the years 1971-1973. Med Pr 1976:39 50. (In Polish.)

22 Thomson D. Sickness absence in the civil service. Proc $R$ Soc Med 1972;65:572-7.

${ }^{23}$ Whitehead FE. Recent trends in certified sickness absence. Proc $R$ Soc Med 1972;65:567-72.

${ }^{24}$ Petermann A, Kneist W. The influence of social factors on the absenteeism due to disease of working women. Sante Publique (Bucur) 1977; 20:275-86. (In German.)

${ }^{25}$ Taylor PJ, Burridge J. Trends in death, disablement and sickness absence in the British Post Office since 1891. Br J Ind Med 1982; 39:1-10.

${ }^{26}$ Erlam AR. Sickness absence in drivers of London taxis and buses. J Soc Occup Med 1982;32:20-5.

${ }^{27}$ Shellart Hokkeling PCM, Schellart NAM. Absenteeism of the working married women. Tijdschrift voor Sociale Geneeskunde 1977;55:42-50. (In Dutch.)

${ }^{28}$ Kavoussi N, Miller HJ, Rezvani A. The effect of unsatisfactory working conditions on the epidemiology of unauthorised absenteeism in an old textile factory in Isfahan. J Hum Ergol (Tokyo) 1978; 7:81-7.

${ }^{24}$ Tobiasz-Adamczyk B, Flak E. Susceptibility to absence and manifested attitudes toward the work establishment. Przegl Lek 1979;36:481-4. (In Polish.)

${ }^{30}$ Ulrich $\mathrm{H}$. Relations between morbidity due to disablement and job satisfaction-results of a trend analysis. Z Gesamte $\mathrm{Hyg}$ 1980;26:451-7. (In German.)

${ }^{31}$ Baker CC, Pocock SJ. Ethnic differences in certified sickness absence. Br J Ind Med 1982;39:277-82.

${ }^{32}$ Schmidt W. Psychological causes of industrial absences, accidents, and quality deficiencies. $Z$ Arbeitswiss 1976;30:234-9. (In German.)

${ }^{33}$ Nicholson N, Brown CA, Chadwick Jones JK. Absence from work and work satisfaction. J Appl Psychol 1976;61:728-37. 